Verfahren anwandte. Das Deçct der Rinde wurde mit basisch essigsaurem Blei gefällt, die vom Niederschlage getrennte Fliissigkeit theils durch Schwefelsäure, theils durch Schwefelwasserstoff vom Bleigehalt getrennt, und dann verdunstet. Man erhielt ein Lraunes hyrroslropisches nicht bitterschmeckendes Extract, welches in wenig Wasser grelöst und mit vielem Alkohol versetzt wurde, worauf sich nach einiger Zeit eine braune fast geschmachlose Materie absetzte; die davon getrennte Flüssigkeit wurde zur Syrupsconsistenz eingeengt, wodurch eine körnige Masse zurückblieb, die durch $\mathrm{Ab}$ waschen mit Alkohol und wiederholtes Umkrystallisiren gereinigt wurde.

Die Krystalle sind lange, weifse, seidenartig glänzende Nadelı, in Wasser und Alkohol löslich, in Aether unlöslich, und scheinen mit Säuren und Alkalien sich nicht verbinden za können. Sie haben einen sehr wenig bitteren Geschmack und sind im Vasser und Alkohol weniger löslich, als das obenerwähnte Crataegin.

\title{
Ueber das Rhamnin, ein krystallisirbares Princip in den Kreuzdornbeeren;
}

vom

Apotheker Fleury

zu Pontoise.

Man nimmt im Allsemeinen als Bestandtheile der Kreuzdornbeeren an eine färbende Materie, eine Säure, Gummi, Zucker und eine stickstoffhaltige Substanz *). Wird der Saft der Beeren mit Aether und namentlich

*) Der Saft der Kreuzdornbeeren (Baccae Rhamni cathartici) ist früher von $A$. Voge $\mathrm{I}$ untersucht, später von $\mathrm{Hub}$ ert, s. diese Zeitschr. 1. $R$. Bd. XXXIV. S. 142. Letzterer fand darin Essigsäure, Apfelsäure; einen bittern ekelhaft schmekkenden Stoff, der wahrscheinlich der wirksame Bestandtheil und dem Cathartin ahnlich; einen grunen zur Zeit der Reife roth werdenden Farbstoff, durch die darin statt findende Entwicklung der Säuren; einen braunen Farbstoff, der beim Gähren verschwindet, und Zucker. H ubert giobt dem durch Gährung erhaltenen Safte zur Bereitung des Syrup. Spin. cern. den Vorzug vor dem ausgeprefsten, worin ihm viele Praktiker beistimmen. Br. 
mit Terpentinöl behandelt, so werden diese beiden Flüssigkeiten gelb gefärbt.

Der Saft reifer Früchte wurde zur Syprupsconsistenz abgeraucht; er besitzt einen zuckrigen bitteren Geschmack und gährt nicht mehr, wenn man ihr auch mit Hefen versetzt und einer angemessenen 'Temperatur unterwirft; man erhält hierdurch einen sehr wirksamen und wohlfeilen Saft, weil man keinen Zucker zuzusetzen braucht, und man dem durch Auspressen erhaltenen Saft die mehrmals wiederholte Auskochung des Marks der Früchte zusetzen und das Ganze zur Syrupsconsistenz abrauchen kann, denn nach Soubeiran enthält das Mark eine ziemliche Menge der abführend wirkenden Substanzen zurück.

Meine Absicht bei den nachfolgenden Versuchen beschränkt sich darauf, einige Worte iiber die krystallisirbare Substanz der Kreuzdornbeeren zu sagen, welche bis jetzt die Aufmerksamkeit nicht auf sich gezogen hat, und die ich in Folge der oben angeführten Bemerkung Soubeiran's untersucht habe.

Diese krystallisirbare Substanz, welche man Rhamnin nennen kann, existirt in dem Mark der Kreuzdornbeeren wie in dem Saft derselben, aus welchem letztern sie sich absondert bei seiner Bereitung oder nach kürzerer oder längerer Zeit. Es ist die Substanz, welche man oft in voluminösen Kremen, in kleinen Körnern oder blumenkohlähnlichen krystallinischen Gruppen oder f'einen Nadeln in den Standgefälsen des Syrup. Spin. cerv. wahrnimmt. Sie besitzt eine blafsgelbe Farbe, einen eigenthümlichen wenig ausgezeichneten Geschmack, einigermafsen nach Mehlteig, geht nicht in geistige Gährung über, ist in Aether und kaltem Alkohol unlöslich, in kochendem Alkohol leichtlöslich, indem sio den Alkohol wie Mannit unter denselben Umständen zurückhält. In kaltem Wasser ist sie sehr schwer löslich und bläht sich darin nicht auf, beim Kochen aber schwillt sie im Wasser sehr auf und absorbirt davon eine grofse Menge.

In Kali löst sie sich mit schöner safrangelber Farbe auf und mit Entwicklung eines zuckrigen Geschmacks; von Ammoniak, basisch kohlensaurem Kali und basisch kohlensaurem Natron wird sie ebenfalls mit schöner gelber Färbung aufgelöst; setzt man diesen Auflösungen einige Tropfen Schwefelsäure zu, so entfärbt sich die Flïssigkeit sogleich und das Rhamnin wird abgeschieden. 
Verdunstet man die Anflösung des Rhamnins in Kali, so erhält man eine branne auf dem Bruch glänzende Masse, welche ale Teuchtignkeit der Luft wenig anzieht; eine kleine Menge dieser Materie färbt eine grofse Masse Wasser gelb.

Salpetersäure löst in der Kälte das Rhamnin auf, und fïrbt sich dadurch dunkelbraun; durch Verdïnnen behäl die Aufösung ihre Farbe und das Rhamnin bleibt aufgelöst. Schwefelsäure und Salzsänre lösen das Rhamnin in der Kälte ebenfalls auf, färben sich danit aber stark braun; werden diese Auflösungen mit Wasser verdünnt, so behalten sie ihre Farbe nicht, und das Rhamnin wird abgeschieden. Verdünnte Schwefelsäure löst das Rhamnin in der Wärme auf, läfst es aber beim Erkalten wieder fallen.

Die Einwirkung der Salpelersäure auf das Rhamnin beim Kochen ist sehr merkwürdig, denn es bilden sich dadurch drei Substanzen: Oxalsäure, eine bittre gelbe Materie, dic Picrinsäure zu sein scheint, und endlich eine bittre Materie, die man für eine neue Substanz halten möchte. Wird Salpetersäure mit Rhamnin erhitzt, so färbt sie sich dunkelbraun; eine Secunde daxauf entfirbt sick die Substan\% merklich. und bei forigesetztem Frhitzen wirl sie bald blarsgelb. Durch Abrauchen der Auflösung erhält man eine krystallinische Masse, die sich in Wasser gröfstentheils und mit schön gelber Farbe auflöst; der ungelöste Theil erscheint in Form eines Pulvers orler gelber Filamente, von anhaltend sehr bitterm Geschmack. Wenn die Verdunstung weit fortgesetr.twurde, und man setzt schnell kaltes Wasser hinzu, so bildet sich eine Menge kleiner gelber Krystalle, und der aufgelöste Theil besteht meist aus Oxalsiure. Die von der Oxalsä̉ure und der bittern Materie unabhängigen Krystalle haben folgende Eigenschaften : sie bilden gelbe lisue farnlirautförmig gruppirte nadelförnigge Krystalle; in kaltem Wasser sind sie schwerlöslich, in warmem leichtlöslich. Die Auflüsung verändert Kali-, Eisenund Kupfersal\%e, Alam, essigsaures Bleioxyd, Chlorbaryum, salpetersaures Silberoxyd und Quecksilberchlorid nicht. Durch Schwefelsäure und Chlorwasserstoflsäure werden die Krystalle entfärbt, behalten aber dieselbe Krystallisationsart. In Ammoniak sind sie leichtlöslich mit safrangelber Färbung; läfst man die Auflïsung an der Sonne verdansten, so scheidet sie sich in zwei Theile; der eine krystallisirt in langen goldgelben Nadeln, der andere bildet eine unlrystallisirte orangegelbe Masse. 
Zur Darstellung des Rhamnins werden noch mehre Methoden als die von mir angewandte dienen können, denn man erhält, darnach sehr wenig. Mein Verfahren ist folgendes:

Man lïst die noch etwas grünen Kreuzdornbeeren auspressen, das Mark mit Wasser auskochen und das colirte Decoct erkalten; nach einigen Tagen setzt sich dann eine krystallinische blumenlrohlähnliche Masse $a b$; man laifst das Mark zwei bis dreimal auskochen, bei jeder Operation erhält man eine neve Quantität Rhamnin, welches man zusammen auf Leinwand sammelt und ausdrückt. Die vorher so voluminöse Masse wird hierdurch auf eine Kleinigkeit zurückgeführt. Man behandelt die Substanz mit liochendem Alkohol und läst heifs filtriren, worauf das Rhamnin beim Erkalten auskrystallisirt. Zur völligen Reinigung kann man es anch noch mit gewaschener Thierkohle behandeln.

Während der Gährung des líreazdornbeerensaftes sammelt sich eine gewisse Menge Rhamnin anf der Ober. fläche der Flüssigkeit, wclches man aber wie das mit dern Mark erhaltene reinigen kann. Uebrigens erhält man aus dem Safte weniger und unreineres Rhamnin als durch Auskochen des Markes. (Journal de Pharmacie XXVIl. 666.)

\section{Zweiter $A b s c h n i t$.}

\section{Centralbericht. Proteinverbindungen.}

DTehre Verbindungen der Proteinschwefelsäure *) hat Mulder einer Untersuchung unterworfen. Die Säure wurde durch Behandlung von gereinigtem Käsestoff mit concentrirter Schwefel säure, Auswaschen u. s. w. dargestellt. Die reine Säure wurde in Ammoniak gelöst, der Ammonialiüberschurs durch Abdanıpfen entFernt und die Auflösmng dieser Verbindung mit den entsprechenden Metallsalzen zersetzt.

Das proteinschwefelsaure Silberoxyd zeigte folgende Zusammensetzung:

*) S. dieses Archiv 2 R. Bd. XXV. 202.

Arch. d. Pharm. II. Reihe. XXVIII. Bds. 3. Hft. 